\title{
OPEN LABEL STUDY OF INTENSIVE VASOPRESSORS THERAPY IN CRITICAL CARE- SURVIVAL BENEFITS vs SIDE EFFECTS

\author{
Pranay Bajpai ${ }^{1}{ }^{*}$, Akshat Pandey ${ }^{1}$, Arvind Mittal ${ }^{1}$, R.K.Jha ${ }^{1}$, V.P.Pandey ${ }^{2}$ \\ ${ }^{1}$ Department of Medicine, Sri Aurobindo Medical College \& PG Institute, Indore, Madhya Pradesh, India \\ ${ }^{2}$ Mahatma Gandhi Memorial Medical College, Indore, Madhya Pradesh, India
}

\begin{abstract}
Introduction: Among the vasopressor Dopamine and Norepinephrine are most widely used. Till date there is a continuing controversy about whether one agent is superior to the other.

Method: This was a prospective randomized trial conducted in a 12 bedded ICU at a tertiary care center from 1st August 2014 to 31stAugust 2015 a total of 1046 patients requiring a vasopressor were randomized, received either Dopamine or Norepinephrine as the first drug of choice to maintain target Mean arterial Pressure.The outcome of the trial at the end was the rate of death at 28 days. Further at the end we would also see the adverse events due to drug and mortality during ICU stay and number of days stay in the ICU and hospital.
\end{abstract}

Result: In the study 521 were assigned to receive Dopamine and 525 were assigned to receive Norepinephrine. The 28 days mortality in Dopamine arm was $51.6 \%$ (269/521) and in Norepinephrine arm was $47.2 \%(248 / 525)$. Arrhythmias was seen more in Dopamine arm (26.12\%) compared to Norepinephrine arm (14.40\%). Mortality during ICU stay was more in patients who receive Dopamine (51.6\%) then to patients who receive Norepinephrin $(46.1 \%)$ although this difference was not statically significant (P-value $>0.05)$. Further the length of stay in ICU and in hospital was more in patients who received Dopamine $(59.20 \%)$ than Norepinephrin $(57.30 \%)$ but it was statically not significant (P-value $>0.05$ ).

Conclusion: Dopamine when compared with norepinephrine in this study was associated with more arrhythmias and with an increased rate of death in the subgroup of patients with cardiogenic shock. Although the rate of death did not differ significantly between the group of patients treated with dopamine and the group treated with norepinephrine.

Keywords: Vasopressor, Dopamine, Norepinephrine, Arrhythmias, cardiogenic shock

\section{INTRODUCTION}

Shock is best defined as a life-threatening, generalized form of acute circulatory failure associated with inadequate oxygen utilization by the cells. ${ }^{1}$ Circulatory shock is a life-threatening condition that is associated with high mortality In the literature, the reported incidence of septic shock has varied between $6.3 \%$ and $14.7 \%$ of ICU admissions. The mortality rate reported in cases of septic shock was 40 to $60 \% .^{2,3}$ The incidence of shock complicating acute myocardial infarction (AMI) has been relatively stable between $6 \%$ and $9 \% .{ }^{6,7,8,9,10}$ adrenergic agents are frequently required to correct hypotension. Among these agents,

\footnotetext{
*Corresponding author:

Email: dr.pranaybajpai@gmail.com
}

http://dx.doi.org/10.20530/IJTA 32 1-4

ISSN 2320-138X (c) 2016 dopamine and norepinephrine are used most frequently. Guidelines and expert recommendations suggest that either agent may be used as a firstchoice vasopressor in patients with shock. ${ }^{11-13}$ However, observational studies have shown that the administration of dopamine may be associated

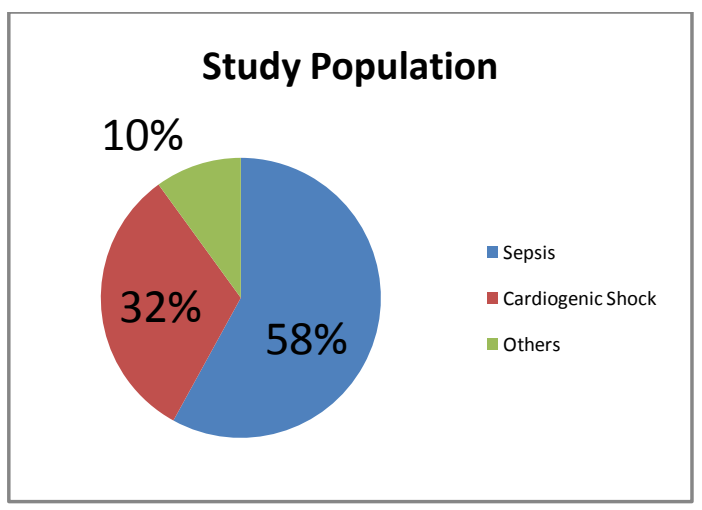

Figure-1 Showing the distribution of patients in the study on the basis of their Diagnosis 


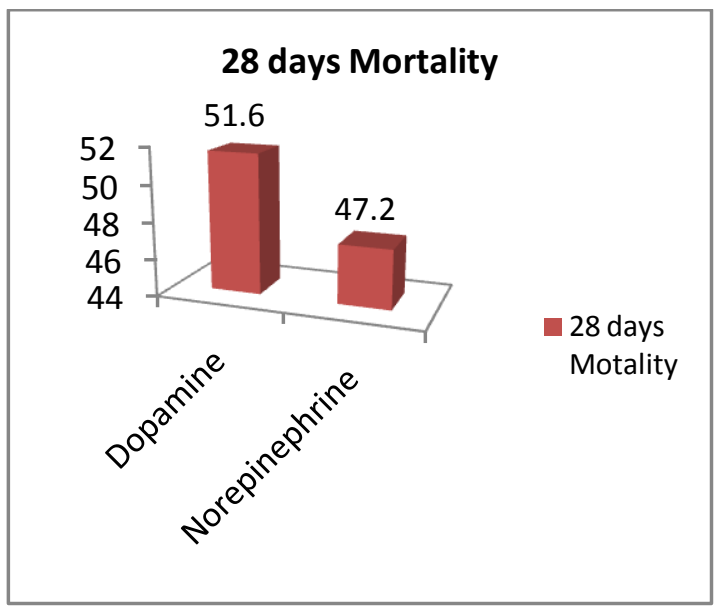

Figure-2 Showing the 28 days mortality in Dopamine group and Norepinephrin group

with rates of death that are higher than those associated with the administration of norepinephrine. ${ }^{14-15}$ Thus our aim was to conduct a study to evaluate the response of two vasopressors: Dopamine and Norepinephrine in patients of shock. Further to study the Survival rates and the adverse outcomes from either of the two drugs in patients of shock.

\section{METHOD}

This was a prospective randomized trial conducted in a 12 bedded ICU at SAMC \& PGI, Indore, (M.P.) a tertiary care center from $1^{\text {st }}$ August 2014 to $31^{\text {st }}$ August 2015. The inclusion criteria of the study were Age 18 years and above, Patients with shock (signs of tissue hypoperfusion indicated by systolic blood pressure $<90 \mathrm{~mm} \mathrm{Hg}$ or MAP $<70$ $\mathrm{mm} \mathrm{Hg}$, Patients with Septic shock, Cardiogenic shock and other types of shock (distributive, obstructive,Hypovolemic shock). Exclusion criteria of the study were Younger than 18 years of age, patients who have already received a vasopressor agent (dopamine, norepinephrine, epinephrine, or phenylephrine) for more than 4 hours during the current episode of shock. Patients who have arrhythmia like atrial fibrillation (>160 beats per minute) or ventricular tachycardia; or had been declared brain-dead. A total 1046 patients requiring a vasopressor were randomized, recieved either dopamine or Norepinephrine. The solutions of norepinephrine or dopamine were prepared in vials or syringes according to the preference of the local ICU. Each vial or syringe was then labeled. The trial was approved by the ethics committee at each participating center. Written informed consent was obtained from all patients or next of kin. The Acute Physiology and Chronic Health Evaluation II (APACHE II) score and the Sequential Organ Failure Assessment (SOFA) score was calculated daily for the first 7 days and then at 28 days. Patients received either dopamine which was started at a dose of 5 $\mathrm{mcg} / \mathrm{kg} / \mathrm{min}$ which could be increased incrementally to a maximum dose of $20 \mathrm{mcg} / \mathrm{kg} / \mathrm{min}$, or Norepinephrine, started at $0.02 \mathrm{mcg} / \mathrm{kg} / \mathrm{min}$ and increased to a maximum dose of $0.12 \mathrm{mcg} / \mathrm{kg} / \mathrm{min}$. The primary end point of the trial was the rate of death at 28 days. Secondary end points were the adverse events due to drug and mortality during ICU stay and stay in the hospital. The statistical analysis was done by use of SPSS software; version 13.0 (SPSS).All reported $\mathrm{P}$ values are two-sided and have not been adjusted for multiple testing.

\section{RESULT}

In the study 521 were assigned to receive Dopamine and 525 were assigned to receive Norepinephrine. Of all the patients included in the study 58\% (607/1046) were diagnosed as sepsis, 32\% $(335 / 1046)$ are of Cardiogenic Shock and 10\% (104/1046) were Obstructive Shock.(Figure-1) The 28 days mortality (Figure-2) in Dopamine arm was $51.6 \%$ (269/521) and in Norepinephrine arm was 47.2\% (248/525). Arrhythmias (Figure-3)were seen more in Dopamine arm (26.12\%) compared to Norepinephrin arm (14.40\%). Mortality during ICU stay was more in patients who receive Dopamine $(51.6 \%)$ then to patients who receive Norepinephrin (46.1\%) although this difference was not statically significant ( $P$-value $>0.05$ ). Further the length of stay in ICU and in hospital was more in patients who received Dopamine (59.20\%) than Norepinephrin $(57.30 \%)$ but it was statically not significant ( $P$-value $>0.05)$.

\section{DISCUSSION}

No significant difference in the rate of death at 28 days between patients who received dopamine and those who received norepinephrine. Dopamine was associated with more arrhythmic events than was norepinephrine, and arrhythmic events that were severe enough to require withdrawal from the study were more frequent in the dopamine group. In addition, dopamine was associated with a significant increase in the rate of death in the predefined subgroup of patients with cardiogenic shock. Observational studies have shown higher death rates with dopamine than with norepinephrine in patients 


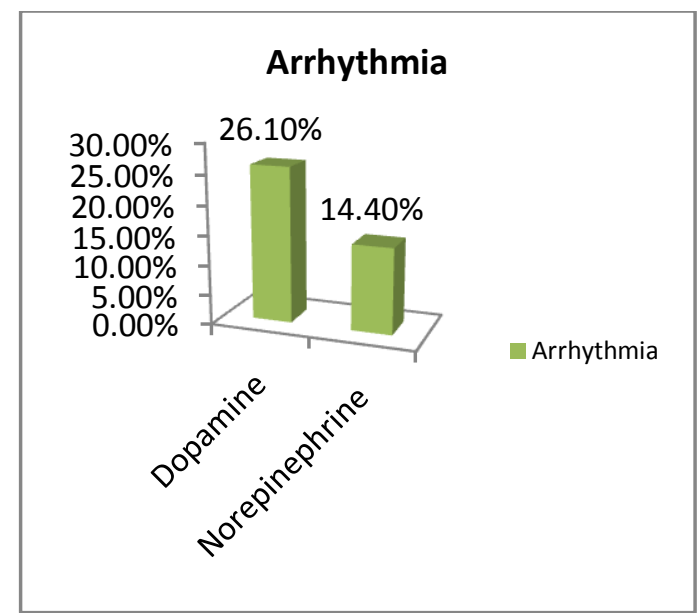

Figure-3, Showing the Prevalence of Arrhythmias in Dopamine group and Norepinephrine group

with shock; the few randomized trials to date have been too small to provide meaningful data. The rate of death at 28 days in this study was close to $50 \%$, which is to be expected in a study with very few exclusion criteria and is similar to the rate in previous observational studies. Smaller observational studies have suggested that treatment with dopamine may be detrimental to patients with septic shock. ${ }^{16-19}$. The exact cause of the increased mortality cannot be determined, but the early difference in the rate of death suggests that the higher heart rate with dopamine may have contributed to the occurrence of ischemic events. Whatever the mechanism may be, these data strongly challenge the current American College of Cardiology-American Heart Association guidelines, which recommend dopamine as the first-choice agent to increase arterial pressure among patients who have hypotension as a result of an acute myocardial infarction. ${ }^{20}$ The sepsis guidelines now recommend norepinephrine as the first-line vasopressor in shock. ${ }^{14}$

\section{CONCLUSION}

Dopamine when compared with norepinephrine in this study was associated with more arrhythmias and with an increased rate of death in the subgroup of patients with cardiogenic shock. Although the rate of death did not differ significantly between the group of patients treated with dopamine and the group treated with norepinephrine, this study raises serious concerns about the safety of dopamine therapy. The limitation of Study were (i) Dobutamine and other vasopressors were not included in the study studied (ii) Hydrocortisone given to patients of septic shock were not included in studied \& (iii) Unclear how frequent supportive interventions (eg, intraaortic balloon pumps) were used but not included in the study.

\section{REFERENCES}

1. Linde-Zwirble WT, Angus DC. Crit Care. 2004;8(4):222. Available from: http://dx.doi.org/10.1186/cc2917.

2. Varpula M, Tallgren M, Saukkonen $\mathrm{K}$, Voipio-Pulkki L$\mathrm{M}$, Pettilä V. Hemodynamic variables related to outcome in septic shock. Intensive Care Medicine. 2005 Jun 23;31(8):1066-71. Available from: http://dx.doi.org/10.1007/s00134-005-2688-z.

3. Marchick MR, Kline JA, Jones AE. The significance of non-sustained hypotension in emergency department patients with sepsis. Intensive Care Medicine. 2009 Feb 24;35(7):1261-4. Available from: http://dx.doi.org/10.1007/s00134-009-1448-x.

4. Bertorello AM, Sznajder JI. The Dopamine Paradox in Lung and Kidney Epithelia. Am J Respir Cell Mol Biol. 2005 Nov;33(5):432-7. Available from: http://dx.doi.org/10.1165/rcmb.2005-0297tr.

5. Linde-Zwirble WT, Angus DC. Crit Care. 2004;8(4):222. Available from: http://dx.doi.org/10.1186/cc2917.

6. American College of Chest Physicians/Society of Critical Care Medicine Consensus Conference. Critical Care Medicine, 1992 Jun;20(6):864-74. Available from: $\quad$ http://dx.doi.org/10.1097/00003246199206000-00025.

7. Hands ME, Rutherford JD, Muller JE, Davies G, Stone $\mathrm{PH}$, Parker $\mathrm{C}$, et al. The in-hospital development of cardiogenic shock after myocardial infarction: Incidence, predictors of occurrence, outcome and prognostic factors. Journal of the American College of Cardiology. 1989 Jul;14(1):40-6. Available from: http://dx.doi.org/10.1016/0735-1097(89)90051-x .

8. Holmes DR, Bates ER, Kleiman NS, Sadowski Z, Horgan JHS, Morris DC, et al. Contemporary reperfusion therapy for cardiogenic shock: The GUSTO-I trial experience. Journal of the American College of Cardiology. 1995 Sep;26(3):668-74. Available from: http://dx.doi.org/10.1016/0735-1097(95)00215-p .

9. Goldberg RJ, Samad NA, Yarzebski J, Gurwitz J, Bigelow C, Gore JM. Temporal Trends in Cardiogenic Shock Complicating Acute Myocardial Infarction. N Engl J Med. 1999 Apr 15;340(15):1162-8. Available from:

http://dx.doi.org/10.1056/nejm199904153401504.

10. Goldberg RJ, Gore JM, Thompson CA, Gurwitz JH. Recent magnitude of and temporal trends (19941997) in the incidence and hospital death rates of cardiogenic shock complicating acute myocardial infarction: The second National Registry of 
Myocardial Infarction. American Heart Journal. 2001 Jan;141(1):65-72. Available from: http://dx.doi.org/10.1067/mhj.2001.111405.

11. Sakr Y, Reinhart K, Vincent J-L, Sprung CL, Moreno R, Ranieri VM, et al. Does dopamine administration in shock influence outcome? Results of the Sepsis Occurrence in Acutely III Patients (SOAP) Study*. Critical Care Medicine. 2006 Mar;34(3):589-97. Available from: http://dx.doi.org/10.1097/01.ccm.0000201896.45809 .e3.

12. Practice parameters for hemodynamic support of sepsis in adult patients in sepsis. Critical Care Medicine. 1999 Mar;27(3):639-60. Available from: http://dx.doi.org/10.1097/00003246-19990300000049.

13. Dellinger RP, Levy MM, Carlet JM, Bion J, Parker MM, Jaeschke $R$, et al. Surviving Sepsis Campaign: International guidelines for management of severe sepsis and septic shock: 2008. Intensive Care Medicine. 2007 Dec 4;34(1):17-60. Available from: http://dx.doi.org/10.1007/s00134-007-0934-2.

14. Martin C, Viviand X, Leone $M$, Thirion X. Effect of norepinephrine on the outcome of septic shock. Critical Care Medicine. 2000 Aug;28(8):2758-65. Available from: http://dx.doi.org/10.1097/00003246200008000-00012.

15. Boulain T, Runge I, Bercault N, Benzekri-Lefevre D, Wolf $\mathrm{M}$, Fleury $\mathrm{C}$. Dopamine therapy in septic shock: Detrimental effect on survival? Journal of Critical Care. 2009 Dec;24(4):575-82. Available from: http://dx.doi.org/10.1016/j.jcrc.2008.11.003.
16. Vincent J-L, Moreno R, Takala J, Willatts S, De Mendonça A, Bruining $H$, et al. The SOFA (Sepsisrelated Organ Failure Assessment) score to describe organ dysfunction/failure. Intensive Care Medicine. 1996 Jul;22(7):707-10. Available from: http://dx.doi.org/10.1007/bf01709751.

17. Wheeler AP, Bernard GR. Treating Patients with Severe Sepsis. N Engl J Med. 1999 Jan 21;340(3):207$14 . \quad$ Available from: http://dx.doi.org/10.1056/nejm199901213400307.

18. Beale RJ, Hollenberg SM, Vincent J-L, Parrillo JE. Vasopressor and inotropic support in septic shock: An evidence-based review. Critical Care Medicine. 2004 Nov;32(Supplement):S455-S465. Available from: http://dx.doi.org/10.1097/01.ccm.0000142909.86238 .b1.

19. KNAUS WA, DRAPER EA, WAGNER DP, ZIMMERMAN JE. APACHE II. Critical Care Medicine. 1985 Oct;13(10):818-29. Available from: http://dx.doi.org/10.1097/00003246-19851000000009.

20. Antman EM. ACC/AHA Guidelines for the Management of Patients With ST-Elevation Myocardial Infarction--Executive Summary: A Report of the American College of Cardiology/American Heart Association Task Force on Practice Guidelines (Writing Committee to Revise the 1999 Guidelines for the Management of Patients With Acute Myocardial Infarction). Circulation. 2004 Aug 3;110(5):588-636. Available from: http://dx.doi.org/10.1161/01.cir.0000134791.68010.f a 